\title{
Feature
}

\section{A Useful How-To Guide for Course and Curricula Revisions}

\author{
Review of: Designing and Assessing Courses and Curricula: A Practical Guide, by \\ Robert M. Diamond; 1998; 321 pp.; Jossey-Bass (San Francisco); ISBN: 0-7879-1030-9
}

\author{
Reviewed by Joyce K. Ono, Department of Biological Science, California State \\ University, Fullerton
}

The explosive changes in the biological sciences in the past two decades and results of research on how people learn have led many faculty to reevaluate the content, delivery, and effectiveness of traditional biology courses and curricula (e.g., see the $C B E$, Summer 2003 review by Doug Fambrough of the Bio2010 report). Change is never easy, however, and most faculty in higher education are ill equipped to initiate and implement major curricular revisions without some guidance or a model. Robert Diamond's revised work provides a model for effecting change, a model that has many of the elements that we successfully used in a major revision of the biology core curriculum at Cal State Fullerton University.

When I was asked to review Diamond's book because of our experience in transforming our curriculum, its title sounded vaguely familiar. Indeed, I discovered that I had bought it back in 1998, at the same time that I had naively accepted the task of overseeing the curricular revision for our department by being elected vice chair. When I reread the book for this review, I even discovered the Post-It note that marked where I had presumably quit reading: Chapter 12, "Selecting and Using Technology." In rereading the book, after five arduous years of the meetings, grant writing, faculty retreats, surveys, presentations, and reports that led to full implementation of our new curriculum in 2003, I found that we had employed many of the same processes that are described in Diamond's model. Thus, this book would provide a useful starting point for others embarking on curricular change.

Gathered here are the important considerations, procedural guides, and references needed to systematically initiate and implement curricular and course revisions to establish a learner-centered program, that is, a curriculum or course that focuses not only on content, but also incorporates research findings on how students learn and assessments to monitor the effectiveness of the program to enable continual improvements. Although this goal was new to us back in the mid-1990s, we came to embrace it as we discovered that focusing only on content could not address the problems of low retention, both in terms of the number of majors completing the core courses and in the lack of students'

DOI: $10.1187 /$ cbe. $04-08-0050$

Address correspondence to: Joyce K. Ono (jono@fullerton.edu). conceptual knowledge in upper division courses. Moreover, we found that focusing on the content of our courses was divisive and inefficient: We invariably ended up with impossibly long lists of facts and principles, oftentimes with individuals adamant of the importance of their particular area of expertise, resulting in "turf wars."

Diamond's model for developing a learner-centered curriculum or course consists of five stages: 1) determining the need to change; 2) identifying goals or desirable outcomes; 3) designing the curriculum or instruction to attain these goals and the assessments that will provide the necessary feedback about the attainment of goals; 4) implementation and assessment (which feeds back to the goals statement); and 5) revision based on the results of the assessment. He asserts that this model is flexible and can be used in a variety of campuses and local situations. In Chapter 2 , the processes, roles of those involved, and the rationale for each stage of the model are further elucidated; Chapters 3 to 12 provide details for accomplishing the first three stages. Chapters 13 ("Developing a Learning-Centered Syllabus") and 14 ("Cultivating a Respect for Diversity") are geared toward course design issues. Chapter 15 focuses on the final stages of Diamond's model, namely, implementation, evaluation, and refinement of the course or curriculum. The final chapter ("Learning from Experience") reiterates the major components of the model based on Diamond's personal experiences and stresses the need for an overall vision and systematic approach for success.

As a professor of instructional design, development, and evaluation and of higher education at Syracuse University in New York, Robert M. Diamond has the credentials and experience for writing this book. For more than 20 years, he was assistant vice chancellor of the Center for Instructional Development. He also served as a consultant to numerous colleges and universities, and a Web search (http://www. thenationalacademy.org/About/principals.html) revealed that he is currently serving as president of the National Academy for Academic Leadership in St. Petersburg, FL. Despite his own roles in administration, Diamond clearly intends faculty to be the main audience of this book. Therefore, it directly addresses many of the concerns facing faculty involved in the time sink that curricular and course revision require, including how to justify involvement in 
curricular and course development as scholarly activity and not mainly as part of their usual teaching (part of Chapter 1). Consistent with this perspective, Diamond has been a national proponent in effecting changes in faculty reward systems, as well as an author of a guide for faculty undergoing the promotion and tenure process.

Diamond emphasizes the need for flow-chart-type diagrams to visualize and effectively communicate processes and their interrelationships, and he follows his own advice by using many such diagrams throughout the book. Like a true how-to book, there is even an exercise to convert a text description of a problematic course into a diagram (Chapter 2, "Systematic Design: Model and Benefits"). Because descriptors are not provided in the figure legends, however, many of these diagrams are not clear unless you refer back to the text. In addition, there are some instances in which the figures are not clearly separated from the text, making it difficult to find the continuation of a paragraph or a bulleted list. Despite the distraction of the formatting, our experiences support Diamond's focus on effective graphical communication. For example, in our curricular revision project, we also made extensive use of process diagrams, organizational charts, and matrices in presentations, grants, reports, and advising documents.

The book presents a variety of case studies as examples and I found myself skimming these unless they directly pertained to our situation or discipline. Nevertheless, having concrete examples is helpful and provides support that the model works in a variety of situations and disciplines. The appendix includes longer case studies, as well as useful forms and surveys. A cross-reference that related the appendices to specific parts of the book would have been useful, although the purposes of many are obvious (e.g., "Resource D: Sample Alumni Survey for Evaluating Program Effectiveness and Needs").

Discussion of curricular and course transformations are combined throughout the book, although it is a more useful guide for curricular redesign. Because courses are integral to a curriculum, the presentation of both together is easily justified, and the model can be applied to both. Curricular revisions are by nature much larger in scope, however, and require the involvement of many individuals and greater resources. Not unexpectedly, then, there are times when the descriptors and processes in the book are not appropriate to both.

Several key factors in our experience in curricular reform concur with Diamond's model. First, we also found that the success of the project hinges on teamwork among faculty. In our effort, we organized almost all of the faculty in the department into collaboratives to develop the learning goals for each of the new core courses. This involvement also led to ownership and stewardship of the product. Second, we also discovered that an external facilitator is a key member of the team. For our process, we employed a professional facilitator with experience both in developing processes for attaining goals through consensus and who could also question our assumptions without being divisive. Finally, we also found that involving administrators and other stakeholders was necessary to generate political support for the project. Communication with administrators, support staff, faculty in other departments, and feeder community colleges and students was necessary to gain acceptance and to garner resources needed for our revisions. In contrast, our process has deviated from that proposed by Diamond with regard to developing appropriate assessments for the new curriculum. In hindsight, we should have addressed assessment strategies at the same time that we identified our learning outcomes. Although we had evaluators involved in the project, they were evaluating the process we were using to effect change, not the products of our labors. It turns out that assessment at the programmatic level is not so easy to do, although we have made progress in this area. For example, in addition to using the Educational Testing Service's Major Field Tests in Biology for assessment of biological content, which is now required of all our graduating seniors, we also have taken time to define what we mean by critical thinking and problem solving in biology to develop appropriate assessments.

Since we first started discussions of revising our core curriculum in 1995, it has taken us seven arduous years to revise our core curriculum and to offer the first two courses sequentially as pilots in 2002. Perhaps if we had been more mindful of Diamond's advice, we could have shortened the process instead of "rediscovering the wheel." In May 2004, we convened representatives from 17 biology departments in the California State University system for a workshop on revising the biology core curriculum (http://www.calstate. edu/itl/proposals/2004_reports.shtml). We provided each campus with a copy of Grant Wiggins' and Jay McTighe's Understanding by Design (Prentice Hall, 2001) as a resource for designing new curricula. In retrospect, after rediscovering Diamond's book, Designing and Assessing Courses and Curricula would have been more comprehensive, practical, and user-friendly. I highly recommend that faculty involved in curriculum or course revision (or better still, those at the contemplation stage) read this book and, unlike me, keep it in a handy place, ready for constant consultation, instead of buried on a sagging bookshelf. 